\title{
Cytoprotective Effect of Heat Shock Protein 27 Against Lipopolysaccharide- Induced Apoptosis of Renal Epithelial HK-2 Cells
}

\author{
Chunmei Lia Jiang Wu ${ }^{b}$ Yuan Lia Guangqun Xing ${ }^{a}$ \\ aDepartment of Nephropathy, ${ }^{b}$ Department of Vascular Surgery, The Affiliated Hospital of Qingdao \\ University, Qingdao, China
}

\section{Key Words}

Heat shock protein 27 (Hsp27) • Lipopolysaccharide (LPS) • HK-2 cells • Septic acute kidney injury (septic AKI) $・ \mathrm{BCl}-2 \cdot \mathrm{NF}-\mathrm{KB} \cdot \mathrm{JNK}$ pathways

\begin{abstract}
Background: In response to various stimuli, heat shock protein 27 (Hsp27) functions as an anti-apoptotic or/and anti-inflammatory factor which confers a survival advantage to cells. This study was aimed to explore whether Hsp27 also has a cytoprotective role in human renal tubular epithelial cells, and to evaluate its potential in treating septic acute kidney injury (septic AKI). Methods: HK-2 cells were subjected to different concentrations (0-10 $\mu \mathrm{g} / \mathrm{mL})$ of lipopolysaccharide (LPS) for various times (0-24 h) to establish a septic AKI model in vitro. Before LPS administration, HK-2 cells were transfected either with vectors or siRNA against Hsp27, and the changes in cell viability and apoptotic cells rate were assessed using CCK-8 and flow cytometry. The expression changes in apoptosis-related proteins, proinflammatory cytokines and chemokine, as well as main factors in NF-KB and JNK pathways were mainly determined by Western blotting. Besides, the relationship between $\mathrm{Hsp} 27$ and $\mathrm{BCl}-2$ was detected by co-immunoprecipitation. Results: LPS remarkably damaged HK-2 cells by reduction of cell viability, induction of apoptosis, and stimulation of proinflammatory cytokines and chemokine release. Hsp27 overexpression significantly impaired LPS-induced damage in HK-2 cells. Hsp27 overexpression couldn't alter the mRNA level of $\mathrm{BCl}-2$, but could interact with $\mathrm{Bcl}-2$ at an endogenous level. Both NF-KB and JNK pathways were activated by LPS, while were blocked in Hsp27-overexpressing cells. Conclusion: Hsp27 overexpression conferred a survival advantage to LPS-injured HK-2 cells by controlling cell viability, apoptosis and inflammation, possibly via interaction with $\mathrm{Bcl}-2$ and modulation of NF-KB and JNK pathways.
\end{abstract}




\section{Introduction}

Sepsis is a syndrome of physiologic, pathologic, and biochemical abnormalities that arises when the body's response to infection injures its own tissues and organs [1]. It has been identified as a life-threatening organ dysfunction, and severe sepsis significantly accelerates physical and neurocognitive decline [2]. Acute kidney injury (AKI) is one of the most common and the most serious complications of sepsis. Septic AKI accounts for 33$50 \%$ of all AKI in adults and $25-50 \%$ of those in children [3]. Patients with septic AKI have a higher burden of illness, greater abnormalities in acute physiology, and greater nonrenal organ failure when compared with nonseptic AKI [4]. Lipopolysaccharide (LPS), the outer membrane component of gram-negative bacteria, has been identified as the major factor that leads to septic AKI [5-7]. LPS injection has been used as exogenous toxin to mimic a septic AKI model [8].

Heat shock protein 27 (Hsp27), a molecular chaperone belonging to the small shock protein group, which is ubiquitously expressed in almost all cells and across species [9]. Intracellular expression of Hsp27 modulates the ability of cells to respond to several types of injury, including heat shock, oxidative stress and chemical stress in order to offset the deleterious effects of cellular stresses $[10,11]$. Hsp27 has also been identified as an antiapoptotic factor which confers a survival advantage to cells by reduction of apoptosis [12, 13]. Diagnostic test study has indicated Hsp27 is a sensitive biomarker for detection of early AKI in critically ill patients [14]. Further, p38MAPK-Hsp27 signaling pathway can be activated by AKI [15]. In mice, Hsp27 overexpression protects against AKI after hepatic ischemia and reperfusion [16]. Despite studies have reported the associations between Hsp27 and AKI, more research is still needed to elucidate detailed functions and mechanisms of Hsp27 in AKI.

In the present study, human renal tubular epithelial cell line HK-2 was used and subject to LPS to mimic a septic AKI in vitro. Hsp27 expression in cells was altered by transfection with vectors or siRNA against Hsp27, the changes in cell viability and apoptosis were then assessed. To explore the possible underling mechanisms, we further detect the relationship between Hsp27 and Bcl-2, the regulatory effects of Hsp27 on proinflammatory cytokines and chemokine as well as on NF- $\mathrm{KB}$ and JNK signaling pathways. This study will provide an improved understanding of Hsp27 and may facilitate the development of strategies for treating septic AKI.

\section{Materials and methods}

\section{Cell culture}

HK-2 cells, possess morphologic characteristics of adult human proximal tubule epithelial cells [17], were purchased from American Type Culture Collection (ATCC, Manassas, VA, USA). HK-2 cells were maintained in a Dulbecco's Modified Eagle's Medium (DMEM): Ham's F-12 (1:1) medium (Sigma-Aldrich, St. Louis, MO) containing $10 \%$ fetal bovine serum (FBS, Gibco, Gaithersburg, MD) [18]. Cells were maintained in humidified atmosphere at $37^{\circ} \mathrm{C}$ with $5 \% \mathrm{CO}_{2}$.

\section{Cell transfection}

HK-2 cells were seeded in 6-well plates at a density of $5 \times 10^{5}$ cells/well for adherence. After $24 \mathrm{~h}$, cells were divided into four groups, namely pc-Hsp27, pc-NC, si-Hsp27 and si-NC. A Hsp27 expression vector (pcHsp27) was constructed by sub-cloning the full-length wild-type Hsp27 coding sequence into pcDNA3.1 $1^{(+)}$ (Sangon Biotech, Shanghai, China), and confirmed by sequencing. The empty construct pcDNA3.1 was transfected as a control (pc-NC). siRNA sequences against Hsp27 and a scrambled control siRNA (RiboBio, Guangzhou, China) were transfected into cells as si-Hsp27 and si-NC group [19]. All transfection were performed using Lipofectamine 3000 reagent (Invitrogen, Carlsbad, CA). Stable transfectants were selected using G418 (Life Technologies, Grand Island, NY).

\section{KARGER}




\section{LPS and cycloheximide (CHX) administration}

HK-2 cells were treated with various concentrations of LPS $(0,0.1,1,2,5$, and $10 \mu \mathrm{g} / \mathrm{mL})$ for $8 \mathrm{~h}$ or with $5 \mu \mathrm{g} / \mathrm{mL}$ LPS for different times $(0,2,4,8,16$, and $24 \mathrm{~h})$.

For inhibition of Bcl-2 protein expression, $200 \mu \mathrm{g} / \mathrm{mL}$ of CHX (a protein synthesis inhibitor; SigmaAldrich) was used to administrate HK-2 cells for $0,3,6,16$ or 24 h post-transfection.

\section{Cell viability assay}

Cell viability was assessed by a Cell Counting Kit-8 (CCK-8, Dojindo Molecular Technologies, Kumamoto, Japan). HK-2 cells or the transfected HK-2 cells were seeded in 96-well plates at a density of 5 $\times 10^{3}$ cells/well. After LPS stimulation, $20 \mu \mathrm{L}$ CCK-8 was added into each well and incubated for $4 \mathrm{~h}$ at $37^{\circ} \mathrm{C}$. The absorbance was measured at $450 \mathrm{~nm}$ using a Microplate Reader (Bio-Rad, Hercules, CA) [20].

\section{Apoptosis assay}

Quantitation of apoptotic cells were performed by using Annexin V-FITC/PI apoptosis kit (BioVision, Milpitas, CA). Briefly, the transfected cells were seeded into 6-well plates at a density of $5 \times 10^{5}$ cells/well and subjected to $5 \mu \mathrm{g} / \mathrm{mL}$ LPS for $8 \mathrm{~h}$. After washing in ice-cold phosphate buffer saline (PBS) for twice, cells were resuspended in $500 \mu \mathrm{L}$ Binding Buffer containing $10 \mu \mathrm{L}$ Annexin V-FITC and $5 \mu \mathrm{L}$ PI. The samples were then incubated in the dark at room temperature for $30 \mathrm{~min}$ and the apoptotic cells (Annexin V-FITC positive and PI-negative) were distinguished on a flow cytometer (BD Biosciences, San Jose, CA).

\section{Quantitative RT-PCR (qRT-PCR)}

Total cellular RNA was extracted by using Trizol reagent (Invitrogen) according to the manufacturer's instructions. Reverse transcription was performed with $2 \mu \mathrm{g}$ of total RNA using a RevertAid First Strand cDNA Synthesis kit (Thermo Scientific, Vilnius, Lithuania). qRT-PCR was conducted in a Bio-Rad CFX96 realtime PCR System (Bio-Rad, CA) by using FastStart Universal SYBR Green Master (ROX) (Roche, USA). All primers were designed and synthetized by GeneCore (Shanghai, China): Bcl-2 (Fw 5'-CGC TGG GAG AAC AGG GTA-3' and Rv: 5'-GGG CTG GGA GGA GAA GAT-3'); IL-1 $\beta$ (Fw 5'-GCT GCT TCC AAA CCT TTG AC-3' and Rv: 5'-GCT TGT GCT CTG CTT GTG AG-3'); TNF- $\alpha$ (Fw 5'-ATA AGA GCA AGG CAG TGG AG-3' and Rv: 5'-TCC AGC AGA CTC AAT ACA CA-3'); IL-6 (Fw: 5'-CAT CTT TGG AAG GTT CAG GTT TGT-3' and Rv: 5'-AGC CCT GAG AAA GGA GAC ATG TA-3'); MCP-1 (Fw 5'-AAG ATC TCA GTG CAG AGG CTC G-3' and Rv: 5'-CCA GGG GTA GAA CTG TGG TTC AA-3'); GAPDH (Fw 5'-CGC ATT GCC AGA CAT ATC AGC-3' and Rv: 5'-AGG TGA AGC AGG CTC AAT CAA-3'). Data were calculated by the $2^{-\Delta \Delta C t}$ method and normalized to GAPDH expression in each sample.

\section{Western blot}

Total cellular protein was extracted using RIPA lysis buffer (Beyotime, Shanghai, China) supplemented with protease inhibitors (Roche) and quantified by BCA ${ }^{\mathrm{Tm}}$ Protein Assay Kit (Pierce, Appleton, WI). The protein sample were separated by sodium dodecyl sulfate-polyacrylamide gel electrophoresis (SDS-PAGE) and transferred to a polyvinylidene fluoride (PVDF, Millipore, Bedford, MA) membrane. Following $1 \mathrm{~h}$ of incubation in 5\% skim milk at room temperature, the membranes were then incubated in the specific primary antibodies against Hsp27, Bax, Bcl-2, pro caspase-9, cleaved caspase-9, pro caspase-3, cleaved

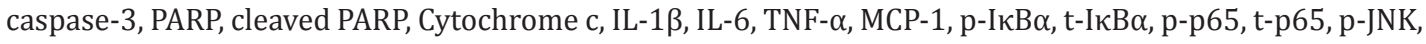
t-JNK, p-c-Jun, t-c-Jun and GAPDH (all from Santa Cruz Biotechnology, Santa Cruz, CA) overnight at $4^{\circ} \mathrm{C}$. The membranes were then incubated in the secondary antibodies (Santa Cruz Biotechnology) for $1 \mathrm{~h}$ at room temperature. Positive signal were developed by ECL Plus Western Blotting Substrate (Piece, Carlsbad, CA) and quantified by Image 1.49 (National Institutes of Health, Bethesda, MD) [21].

\section{Co-immunoprecipitation}

Cells were lysed in RIPA lysis buffer (Beyotime), and the supernatant was collected by centrifugation at $225 \times g$ for $15 \mathrm{~min}$ at $4^{\circ} \mathrm{C}$. The supernatant was then incubated with, anti-Bcl-2 antibody, anti-Hsp27 antibody (Abcam, Cambridge, MA) or the control immunoglobulin (IgG) antibody (Santa Cruz Biotechnology) overnight at $4^{\circ} \mathrm{C}$. Next, $50 \mu \mathrm{L}$ of the samples were mixed with Protein A-Sepharose beads (Life Technology, Carlsbad, CA) and then incubated for $4 \mathrm{~h}$ at $4^{\circ} \mathrm{C}$ with gentle shaking. After centrifugation at $225 \times \mathrm{g}$ for 3 $\min$ at $4^{\circ} \mathrm{C}$, precipitates were subjected to Western blotting analyses for detection of potential interacting proteins [22].

\section{KARGER}


Statistical analysis

Data represent the mean \pm standard deviation (SD) of three independent experiments. Data were analyzed in GraphPad Prism 5.0 software (GraphPad Software, San Diego, CA) by using a one-way analysis of variance (ANOVA). $P<0.05$ was considered to indicate a statistically significant result.

\section{Results}

LPS induces injury in HK-2 cells

HK-2 cells were subjected to different concentrations of LPS $(0,0.1,1,2,5$, and $10 \mu \mathrm{g} /$ $\mathrm{mL}$ ) for $8 \mathrm{~h}$, we found that when the LPS concentration was up to $2 \mu \mathrm{g} / \mathrm{mL}$, cell viability was remarkably decreased $(P<0.01$ or $P<0.001$, Fig. $1 \mathrm{~A})$. Meanwhile, cells were pre-treated with $5 \mu \mathrm{g} / \mathrm{mL}$ LPS for various times $(0,2,4,8,16$, and $24 \mathrm{~h})$, and remarkable decreases of cell viability were observed after $4 \mathrm{~h}$ of LPS stimulation $(P<0.05, P<0.01$ or $P<0.001$, Fig. 1B). These data indicated LPS damaged HK-2 cells in a dose- and time-dependent manner, and $5 \mu \mathrm{g} / \mathrm{mL}$ and $8 \mathrm{~h}$ was selected as two LPS-stimulating conditions for use in the subsequent experiments.

\section{Hsp27 mitigates LPS-induced injury in HK-2 cells}

In order to explore the role of Hsp27 in LPS-injured HK-2 cells, the protein expression of Hsp27 was detected in the LPS-stimulated cells. No remarkable change in Hsp27 level was observed between cells treated with and without LPS (Fig. 2A), suggesting LPS couldn't alter Hsp27 expression. Subsequently, HK-2 cells were transfected either with pc-Hsp27 or si-Hsp27 to overexpress or suppress Hsp27 expression, and transfection efficiency was verified by Western blotting (Fig. 2B). As expected, LPS significantly inhibited cell viability and induced apoptosis $(P<0.001)$, Hsp27 overexpression alleviated the effects of LPS on cells viability and apoptosis $(P<0.05$ or $P<0.01)$, while Hsp27 silencing aggravated these effects $(P<0.05$ or $P<0.01$, Fig. 2C and 2D). Furthermore, apoptosis-related protein expressions in cells were detected, up-regulations of Bax, cleaved caspase-9, cleaved caspase-3, cleaved PARP and cytochrome c, as well as down-regulation of Bcl-2 were observed in the LPS-injured HK-2 cells (Fig. 2E and 2F). Hsp27 overexpression alleviated these abnormal expressions induced by LPS stimulation $(P<0.05, P<0.01$ or $P<0.001)$, but Hsp27 silencing made the abnormal expressions more serious $(P<0.05, P<0.01$ or $P<0.001)$. These results revealed a protective role of Hsp27 in LPS-injured HK-2 cells.

Hsp27 interacts with Bcl-2 at an endogenous level

As results given in Fig. $2 \mathrm{E}$ and $2 \mathrm{~F}$, we found that Bcl-2 protein expression was positively regulated by Hsp27 after LPS stimulation. In order to further determine the relationship

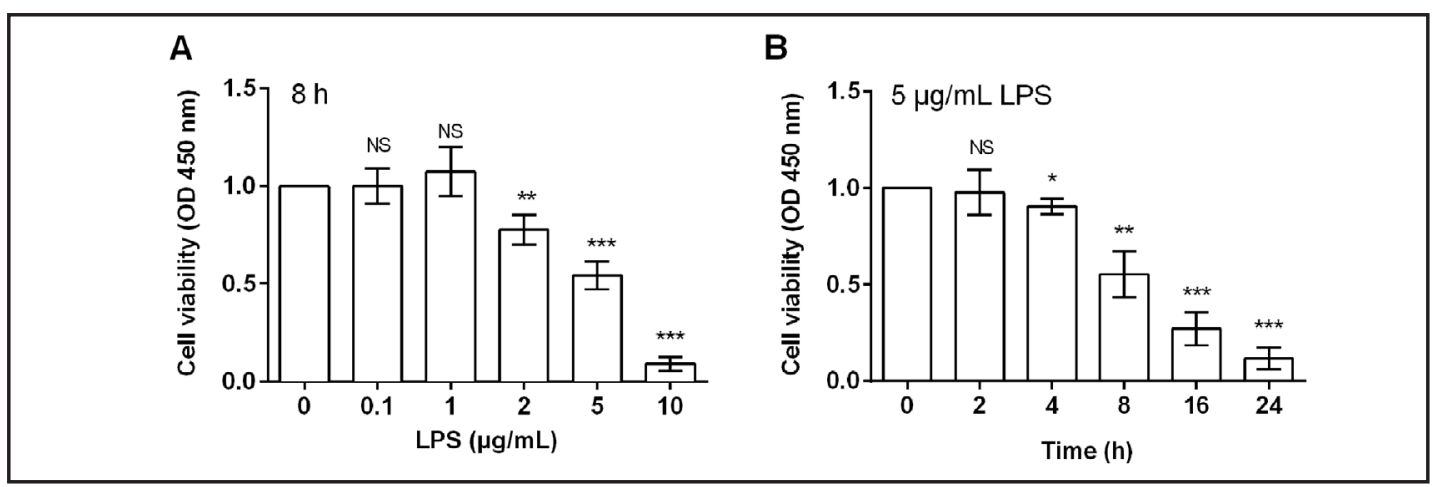

Fig. 1. LPS induces injury in HK-2 cells. HK-2 cells were subjected to (A) different concentrations of LPS (0, $0.1,1,2,5$, and $10 \mu \mathrm{g} / \mathrm{mL}$ ) for $8 \mathrm{~h}$, or subjected to (B) $5 \mu \mathrm{g} / \mathrm{mL}$ LPS for various times $(0,2,4,8,16$, and 24 h), and then cell viability were assessed by CCK-8. NS, no significance; * $\mathrm{P}<0.05$; **, $\mathrm{P}<0.01$; ***, $\mathrm{P}<0.001$. 


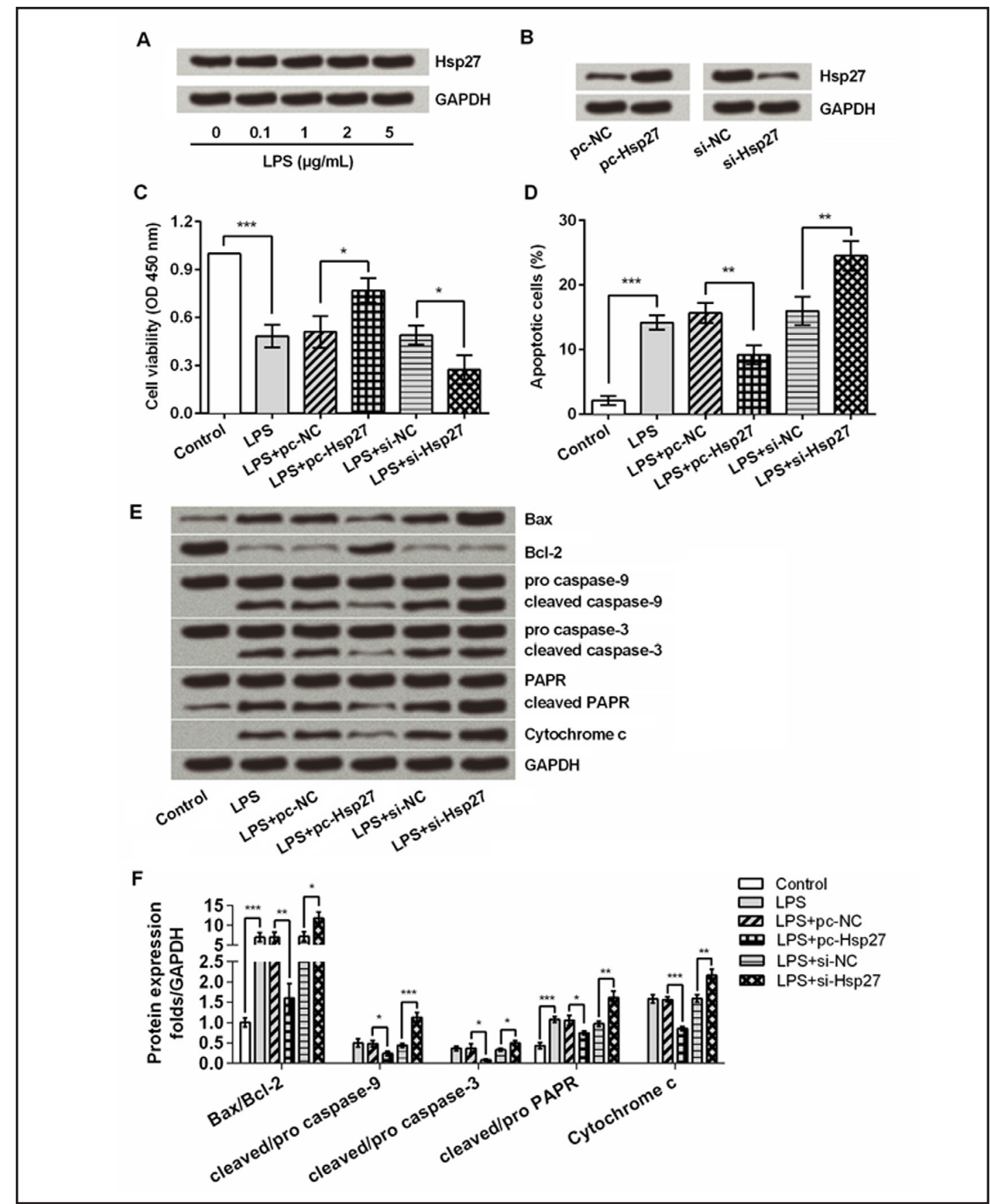

Fig. 2. Hsp27 mitigates LPS-induced injury in HK-2 cells. (A) HK-2 cells were exposed to different concentrations of LPS $(0,0.1,1,2$, and $5 \mu \mathrm{g} / \mathrm{mL})$ for $8 \mathrm{~h}$, and then Hsp37 protein expression was detected by Western blotting. (B) HK-2 cells were transfected with vectors or siRNA against Hsp27, and the transfection efficiency was verified by Western blotting. The transfected HK-2 cells were exposed to $5 \mu \mathrm{g} / \mathrm{mL}$ LPS for $8 \mathrm{~h}$, and then (C) cell viability and (D) apoptosis were respectively assessed by CCK-8 and FITC/PI double-staining. (E) Apoptosis-related protein expressions were detected by Western blotting. (F) Relative protein levels based on Western blot results. *, $\mathrm{P}<0.05$; **, $\mathrm{P}<0.01$; **, $\mathrm{P}<0.001$.

between Hsp27 and Bcl-2, the mRNA level expression of Bcl-2 in the Hsp27-overexpressing cells were detected. We found that overexpression of Hsp27 couldn't alter mRNA level of Bcl-2 $(P>0.05$, Fig. 3A). Co-immunoprecipitation analysis showed that Hsp27 specifically

\section{KARGER}


Fig. 3. Hsp27 interacts with Bcl-2 at an endogenous level. (A) The mRNA level of Bcl-2 in Hsp 27-overexpresssing cells or its negative control cells was determined by qRT-PCR. (B) The interaction between Hsp27 and Bcl-2 at the endogenous level was detected by co-immunoprecipitation. (C) Cycloheximide (CHX, $200 \mu \mathrm{g} / \mathrm{mL}$ ) was used to administrate Hsp27-overexpresssing cells or its negative control cells for $0-24 \mathrm{~h}$, and the protein expression of $\mathrm{Bcl}-2$ was assessed by Western blotting. (D) Relative Bcl-2 level based on Western blot results. NS, no significance; ${ }^{* *}, \mathrm{P}<0.01$.

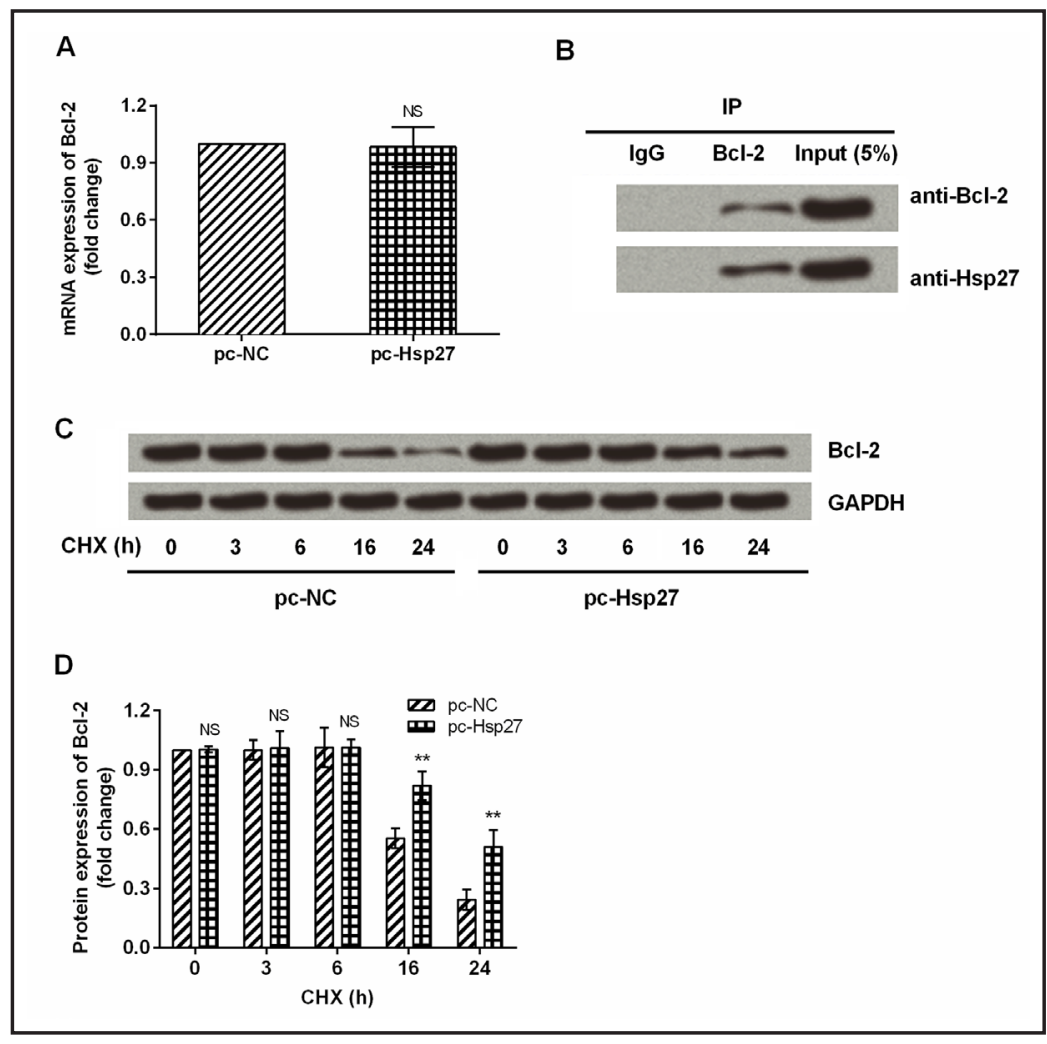

interacted with Bcl-2, but not with the IgG control (Fig. 3B). Additionally, we found that following an administration of CHX on HK-2 cells for 16 and $24 \mathrm{~h}, \mathrm{Bcl}-2$ protein levels were notably decreased, while these decreases were partly abolished by Hsp27 overexpression $(P$ $<0.01$, Fig. 3C and 3D). Taken together, Hsp27 positively regulated Bcl-2 at the translational and/or post-translational levels, but not at the transcriptional level; more importantly, Hsp27 could interact with Bcl-2 at an endogenous level.

Hsp27 diminishes LPS-induced overproduction of proinflammatory cytokines and chemokine

Numerous studies have shown that HK- 2 cells produce IL-1 $\beta$, IL-6, TNF- $\alpha$ and MCP-1 in response to LPS stimulation [23-25]; this was also confirmed in our study. Both the mRNA and protein levels of these proinflammatory cytokines and chemokine produced by HK-2 cells were increased by LPS $(P<0.01$ or $P<0.001$, Fig. 4A-4F). More importantly, Hsp27 overexpression diminished LPS-induced overproduction of these cytokines and chemokine $(P<0.05$ or $P<0.01)$. Hsp27 silencing affected them, expected IL- 6 and MCP-1 proteins, resulted in completely opposite impacts $(P<0.05)$. These data suggested Hsp27 might diminish LPS-induced overproduction of proinflammatory cytokines and chemokine.

NF- $\kappa B$ and JNK signaling pathways are implicated in the effects of Hsp27 on LPS-induced injury

Next, we focused on NF- $\kappa B$ and JNK signaling pathways since these two are thought to be the important pathways involved in the LPS-stimulated inflammation [26, 27]. As results given in Fig. 5A-5D, IкB $\alpha$, p65, JNK and c-Jun were all dramatically activated by LPS $(P<0.01$ or $P<0.001)$. Hsp27 overexpression recovered LPS-induced activation of these four factors $(P<0.01$ or $P<0.001)$. Hsp27 silencing enhanced LPS-induced IкB $\alpha$ and p65 activation $(P$ $<0.05$ or $P<0.01)$, but has no effect on the activation of JNK and c-Jun $(P>0.05)$. These data suggested Hsp27 protected LPS-injured HK-2 cells via modulation of NF-KB and JNK pathways. 
Fig. 4. Hsp27 diminishes LPS-induced overproduction of proinflammatory cytokines and chemokine. HK-2 cells were transfected with vectors or siRNA against Hsp27, and then the mRNA levels of (A) IL-1 $\beta$, (B) IL-6, (C) TNF- $\alpha$ and (D) MCP-1 were detected by qRTPCR. (E) The protein levels of these four factors were detected by Western blotting. (F) Relative protein levels based on Western blot results. NS, no significance; *, $\mathrm{P}<$ 0.05 ; **, $\mathrm{P}<0.01$; ***, $\mathrm{P}<0.001$.
Fig. 5. $N F-\kappa B$ and JNK signaling pathways are implicated in the effects of Hsp27 on LPS-induced injury. HK-2 cells were transfected with vectors or siRNA against Hsp27, and then the protein levels of $(A) p-I \kappa B \alpha$, t-IкB $\alpha$, p-p65, t-p65, and (B) p-JNK, t-JNK, p-c-Jun, t-c-Jun were measured by Western blotting. (C) and (D) Relative protein levels based on Western blot results. NS, no significance; *, P < 0.05; **, P $<0.01{ }^{* * *}, \mathrm{P}<0.001$.
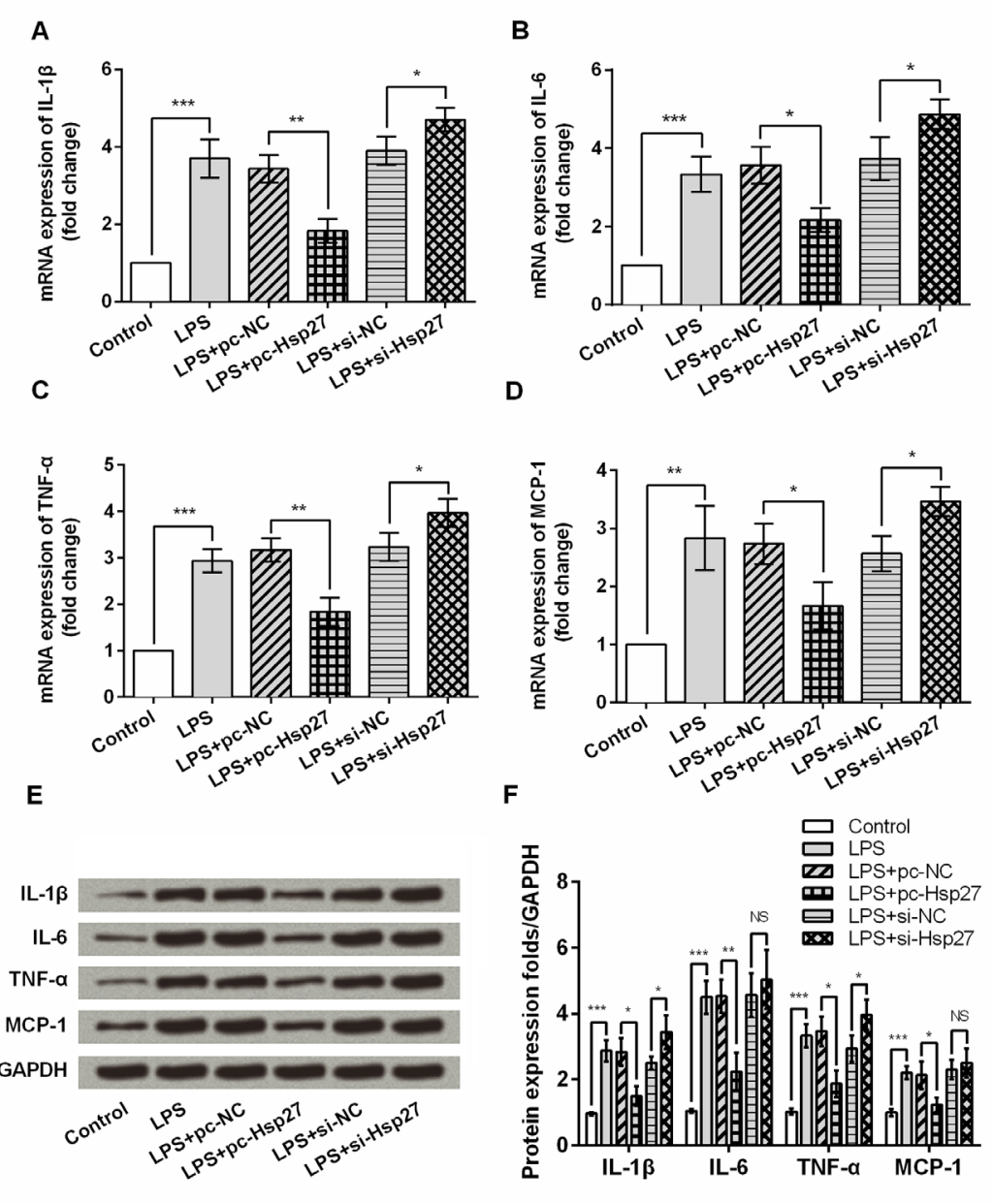

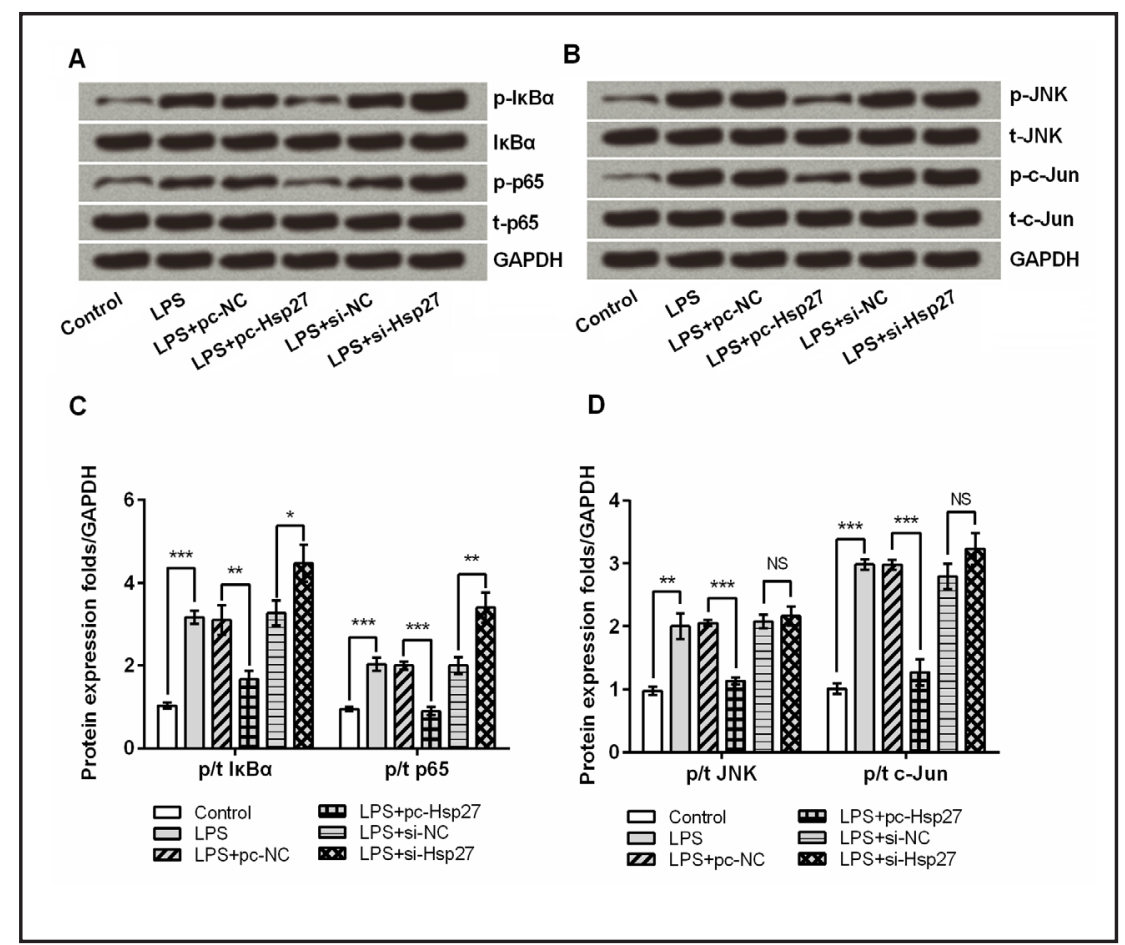




\section{Discussion}

Having previously shown that Hsp27 might represent a predictive marker for early AKI [14], and its overexpression protect against AKI after hepatic ischemia and reperfusion [16]. This study served to depict the detailed functions of Hsp27 on LPS-injured HK-2 cell, an in vitro septic AKI model, as well as to reveal the underlying mechanism of Hsp27-mediated protection in this model. Here, we demonstrated that LPS stimulation induced a remarkable reduce of HK-2 cells viability, an increase of apoptosis and abnormal productions of proinflammatory cytokines and chemokine. Hsp27 overexpression exhibited protective roles in HK-2 cells by impairing LPS-induced damage. In addition, Hsp27 could interact with Bcl-2 and modulate NF- $\mathrm{KB}$ and JNK signaling pathways.

In response to LPS, tubular epithelial apoptosis is induced and caspase-3 is cleaved $[28,29]$, whereas Hsp27 exerts an anti-apoptotic role by inhibition of caspase-dependent apoptosis [10]. In accordance with previous reports, we demonstrated that LPS decreased HK-2 cells viability and induced apoptosis. Overexpression of Hsp27 alleviated the decrease of cell viability and the increase of apoptotic cells ratio to some extent, revealing a protective role of Hsp27 in LPS-induced injury in HK-2 cells. Similarly, overexpression of Hsp27 in hepatocytes could confer remarkable protection against LPS-induced acute liver damage [30].

Several literatures have reported the mechanism of Hsp27-mediated cytoprotection [31]. After pro-apoptotic stress, Hsp27 decreases the ratio of Bax/Bcl-2 which leads to the release of cytochrome c from the mitochondria to the cytosol, finally activating caspase- 3 and resultant apoptosis [31-33]; this was also confirmed in this study. Hsp27 inhibited LPS-induced apoptosis through modulation of Bax/Bcl-2 and caspases. In addition, PAPR, an endogenous substrate for caspases were also inactivated by Hsp27, which further confirmed Hsp27 modulated apoptosis via regulating caspases. Next, we detected the relationship between Hsp27 and Bcl-2, since the balance between renal epithelial cells death and survival is determined by the expression of Bcl-2 [31]. We found Hsp27 could be co-immunoprecipitated with Bcl-2 in HK-2 cells, which for the first time indicated that the interaction of the Hsp27 and Bcl-2 proteins may be responsible for their ability to cooperate in the suppression of apoptosis. However, this hypothesis requires further verification.

It is well known that LPS administration increase the expression of proinflammatory cytokines such as TNF- $\alpha$, IL- $1 \beta$, and IL- 6 , which eventually leading to endotoxemia and sepsis [34]. MCP-1, a chemokine, plays key roles in the recruitment of inflammatory cells into renal interstitium in septic AKI [35]. In this study, all these above mentioned cytokines and chemokine were up-regulated by LPS; more important, Hsp27 overexpression partially abolished these up-regulations induced by LPS. These results indicated an anti-inflammatory role of Hsp27 in LPS-induced AKI. Moreover, it has been reported LPS stimulates cytokines production in the host through NF- $\kappa B$ and JNK activation pathway [26, 27]. In response to various stimuli, Hsp27 functions in the inflammation via activation of these two pathways [36]; this was also confirmed in this study. The activation of NF- $\kappa B$ and JNK pathways induced by LPS stimulation was partially recovered by Hsp27 overexpression.

To sum up, we showed that Hsp27 overexpression conferred a survival advantage to LPS-injured HK-2 cells by controlling cell viability, apoptosis and inflammation. It is likely that Hsp27 exhibited anti-apoptotic and anti-inflammatory roles respectively via interaction with Bcl-2 and modulation of NF- $\mathrm{BB}$ and JNK pathways. These findings will provide support for a cytoprotective role of Hsp27 in septic AKI.

\section{Acknowledgements}

The work was not supported by any funding agency. 


\section{Cellular Physiology Cell Physiol Biochem 2017;41:2211-2220 \begin{tabular}{l|l} 
DOI: 10.1159/000475636 & and Biochemistry 2017 The Author(s). Published by S. Karger AG, Basel \\
wwww.karger.com/cpb
\end{tabular} \\ Published online: April 24, 2017}

\section{Disclosure Statement}

The authors declared that there is no conflict of interests.

\section{References}

1 Singer M, Deutschman CS, Seymour CW, Shankar-Hari M, Annane D, Bauer M, Bellomo R, Bernard GR, Chiche JD, Coopersmith CM, Hotchkiss RS, Levy MM, Marshall JC, Martin GS, Opal SM, Rubenfeld GD, van der Poll T, Vincent JL, Angus DC: The Third International Consensus Definitions for Sepsis and Septic Shock (Sepsis-3). Jama 2016;315:801-810.

2 Angus DC, van der Poll T: Severe sepsis and septic shock. N Engl J Med 2013;369:840-851.

3 Basu RK, Devarajan P: Sepsis-associated acute kidney injury - is it possible to move the needle against this syndrome? J Pediatr (Rio J) 2016;10.1016/j.jped.2016.09.001

4 Bagshaw SM, Uchino S, Bellomo R, Morimatsu H, Morgera S, Schetz M, Tan I, Bouman C, Macedo E, Gibney N, Tolwani A, Oudemans-van Straaten HM, Ronco C, Kellum JA: Septic acute kidney injury in critically ill patients: clinical characteristics and outcomes. Clin J Am Soc Nephrol 2007;2:431-439.

-5 Xu C, Chang A, Hack BK, Eadon MT, Alper SL, Cunningham PN: TNF-mediated damage to glomerular endothelium is an important determinant of acute kidney injury in sepsis. Kidney Int 2014;85:72-81.

6 Chunzhi G, Zunfeng L, Chengwei Q Xiangmei B, Jingui Y: Hyperin protects against LPS-induced acute kidney injury by inhibiting TLR4 and NLRP3 signaling pathways. Oncotarget 2016;10.18632/oncotarget.13010

7 Zhang J, Zhu D, Wang Y, Ju Y: Andrographolide Attenuates LPS-Induced Cardiac Malfunctions Through Inhibition of IkappaB Phosphorylation and Apoptosis in Mice. Cell Physiol Biochem 2015;37:1619-1628. Doi K, Leelahavanichkul A, Yuen PS, Star RA: Animal models of sepsis and sepsis-induced kidney injury. J Clin Invest 2009;119:2868-2878.

-9 Owen S, Zhao H, Dart A, Wang Y, Ruge F, Gao Y, Wei C, Wu Y, Jiang WG: Heat shock protein 27 is a potential indicator for response to YangZheng XiaoJi and chemotherapy agents in cancer cells. Int J Oncol 2016;49:1839-1847.

10 Fatemeh H, Hassan MM, Mojtaba T, Amir A, Jalil TA, Vahid G, Majid GM: Anti-Heat Shock Protein-27 Antibody Levels in Women with Breast Cancer: Association with Disease Complications and Two-Year Disease-Free Survival. Asian Pac J Cancer Prev 2016;17:4655-4659.

-11 Li S, Zhang W, Fan J, Lai Y, Che G: Clinicopathological and prognostic significance of heat shock protein 27 (HSP27) expression in non-small cell lung cancer: a systematic review and meta-analysis. Springerplus 2016;5:1165.

12 Calderwood SK, Khaleque MA, Sawyer DB, Ciocca DR: Heat shock proteins in cancer: chaperones of tumorigenesis. Trends Biochem Sci 2006;31:164-172.

13 Batchelder AJ, Gordon-Weeks AN, Walker RA: Altered expression of anti-apoptotic proteins in non-involved tissue from cancer-containing breasts. Breast Cancer Res Treat 2009;114:63-69.

-14 Morales-Buenrostro LE, Salas-Nolasco OI, Barrera-Chimal J, Casas-Aparicio G, Irizar-Santana S, PerezVillalva R, Bobadilla NA: Hsp72 is a novel biomarker to predict acute kidney injury in critically ill patients. PLoS One 2014;9:e109407.

15 Ma T, Liu XW, Liu Z: Function of the p38MAPK-HSP27 pathway in rat lung injury induced by acute ischemic kidney injury. Biomed Res Int 2013;2013:981235.

-16 Park SW, Chen SW, Kim M, D'Agati VD, Lee HT: Human heat shock protein 27-overexpressing mice are protected against acute kidney injury after hepatic ischemia and reperfusion. Am J Physiol Renal Physiol 2009;297:F885-894.

17 Ryan MJ, Johnson G, Kirk J, Fuerstenberg SM, Zager RA, Torok-Storb B: HK-2: an immortalized proximal tubule epithelial cell line from normal adult human kidney. Kidney Int 1994;45:48-57.

18 Vrbova M, Rousarova E, Bruckova L, Cesla P, Rousar T: Characterization of acetaminophen toxicity in human kidney HK-2 cells. Physiol Res 2016;65:627-635.

19 Fang Y, Zhang H, Zhong Y, Ding X: Prolyl hydroxylase 2 (PHD2) inhibition protects human renal epithelial cells and mice kidney from hypoxia injury. Oncotarget 2016;10.18632/oncotarget.11104

20 Pan XW, Zhao XH: In Vitro Proliferation and Anti-Apoptosis of the Papain-Generated Casein and Soy Protein Hydrolysates towards Osteoblastic Cells (hFOB1.19). Int J Mol Sci 2015;16:13908-13920. 


\section{Cellular Physiology Cell Physiol Biochem 2017;41:2211-2220 \begin{tabular}{l|l} 
DOI: 10.1159/000475636 & $\begin{array}{l}\text { O 2017 The Author(s). Published by S. Karger AG, Basel } \\
\text { www.karger.com/cpb }\end{array}$
\end{tabular}}

21 Ma J, Shui S, Han X, Guo D, Li T, Yan L: microRNA-22 attenuates neuronal cell apoptosis in a cell model of traumatic brain injury. Am J Transl Res 2016;8:1895-1902.

22 Miki T, Zhao Z, Lee CC: Interactive Organization of the Circadian Core Regulators PER2, BMAL1, CLOCK and PML. Sci Rep 2016;6:29174.

-23 Kang JY, Shin HS: Effects of 1,7-substituted methylxanthine derivatives on LPS-stimulated expression of cytokines and chemokines in Raw 264.7 and HK-2 cells. J Microbiol Biotechnol 2015;25:296-301.

-24 Zager RA, Johnson AC, Lund S: 'Endotoxin tolerance': TNF-alpha hyper-reactivity and tubular cytoresistance in a renal cholesterol loading state. Kidney Int 2007;71:496-503.

-25 Xu S, Chen YH, Tan ZX, Xie DD, Zhang C, Zhang ZH, Wang H, Zhao H, Yu DX, Xu DX: Vitamin D3 pretreatment regulates renal inflammatory responses during lipopolysaccharide-induced acute kidney injury. Sci Rep 2015;5:18687.

26 Shirato K, Imaizumi K: Posttranscriptional Suppression of Lipopolysaccharide-Stimulated Inflammatory Responses by Macrophages in Middle-Aged Mice: A Possible Role for Eukaryotic Initiation Factor 2 alpha. Int J Inflam 2014;2014:292986.

-27 Ha T, Hua F, Liu X, Ma J, McMullen JR, Shioi T, Izumo S, Kelley J, Gao X, Browder W, Williams DL, Kao RL, Li C: Lipopolysaccharide-induced myocardial protection against ischaemia/reperfusion injury is mediated through a PI3K/Akt-dependent mechanism. Cardiovasc Res 2008;78:546-553.

28 Zhao YL, Zhang L, Yang YY, Tang Y, Zhou JJ, Feng YY, Cui TL, Liu F, Fu P: Resolvin D1 Protects Lipopolysaccharide-induced Acute Kidney Injury by Down-regulating Nuclear Factor-kappa B Signal and Inhibiting Apoptosis. Chin Med J (Engl) 2016;129:1100-1107.

29 Li S, Guo L, Qian P, Zhao Y, Liu A, Ji F, Chen L, Wu X, Qian G: Lipopolysaccharide Induces Autophagic Cell Death through the PERK-Dependent Branch of the Unfolded Protein Response in Human Alveolar Epithelial A549 Cells. Cell Physiol Biochem 2015;36:2403-2417.

-30 Dai HJ, Li DW, Wang YX, Sun AJ, Lu YX, Ding X, Zhang M, Song YG, Huang XD: Induction of heat shock protein 27 by bicyclol attenuates d-galactosamine/lipopolysaccharide-induced liver injury. Eur J Pharmacol 2016;791:482-490.

-31 Havasi A, Li Z, Wang Z, Martin JL, Botla V, Ruchalski K, Schwartz JH, Borkan SC: Hsp27 inhibits Bax activation and apoptosis via a phosphatidylinositol 3-kinase-dependent mechanism. J Biol Chem 2008;283:12305-12313.

- 32 Tian X, Zhao L, Song X, Yan Y, Liu N, Li T, Yan B, Liu B: HSP27 Inhibits Homocysteine-Induced Endothelial Apoptosis by Modulation of ROS Production and Mitochondrial Caspase-Dependent Apoptotic Pathway. 2016;2016:4847874.

33 Lee SW, Cho JM, Cho HJ, Kang JY, Kim EK, Yoo TK: Expression levels of heat shock protein 27 and cellular FLICE-like inhibitory protein in prostate cancer correlate with Gleason score sum and pathologic stage. Korean J Urol 2015;56:505-514.

-34 Hirschfeld M, Ma Y, Weis JH, Vogel SN, Weis JJ: Cutting edge: repurification of lipopolysaccharide eliminates signaling through both human and murine toll-like receptor 2. J Immunol 2000;165:618-622.

-35 Maier S, Emmanuilidis K, Entleutner M, Zantl N, Werner M, Pfeffer K, Heidecke CD: Massive chemokine transcription in acute renal failure due to polymicrobial sepsis. Shock 2000;14:187-192.

-36 Alford KA, Glennie S, Turrell BR, Rawlinson L, Saklatvala J, Dean JL: Heat shock protein 27 functions in inflammatory gene expression and transforming growth factor-beta-activated kinase-1 (TAK1)-mediated signaling. J Biol Chem 2007;282:6232-6241. 